UNIVALI

UNIVERSIDADE DO VALE DO ITAJAI

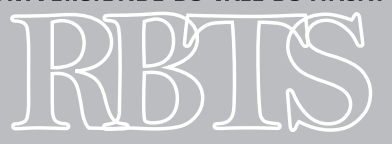

Revista Brasileira de Tecnologias Sociais
1 Graduação em Direito. Mestre em Gestão de Políticas Públicas pela Universidade do Vale do Itajaí.E-mail: aninha37@gmail.com 2 Graduação em História. Mestre e Doutora em Sociologia pela Universidade Federal de Santa Catarina. Professora da Universidade do Vale de Itajaí. E-mail: anaclaudia. univali@gmail.com.

3 Graduação em História. Mestre em História pela Universidade Federal de Santa Catarina e Doutor em História pela Universidade Federal do Rio Grande do Sul. Professor da Universidade do Vale do Itajaí. E-mail:paulo_rmo@hotmail.com.

\section{POLÍTICAS DE ENFRENTAMENTO À VIOLÊNCIA CONTRA AS MULHERES NO MARCO DOS 11 ANOS DE LEI MARIA DA PENHA}

\section{POLICIES TO COMBAT VIOLENCE AGAINST WOMEN TO MARK THE 11-YEAR MILESTONE OF THE MARIA DA PENHA LAW}

\author{
Ana Silvia Serrano Ghisi ${ }^{1}$ \\ Ana Claudia Delfini Capistrano de Oliveira ${ }^{2}$ \\ Paulo Rogério Melo de Oliveira ${ }^{3}$
}

RESUMO: Este artigo contextualiza os avanços da Lei Maria da Penha em relação às políticas públicas de gênero e de enfrentamento à violência contra as mulheres no marco dos 11 anos da implementação desta lei. A pesquisa é resultado da dissertação intitulada "As atribuições das delegacias da mulher de Santa Catarina no contexto das relações de gênero e da política nacional de enfrentamento à violência contra as mulheres", a qual analisou as atribuições normativas das Delegacias da Mulher de Santa Catarina, as normas existentes no âmbito da Polícia Civil catarinense e as novas atividades exigidas da Polícia, previstas na Lei Maria da Penha. Para este artigo, são analisadas as entrevistas realizadas no modelo de pesquisa qualitativa com os/as delegados/as que atuam nas Delegacias da Mulher de Santa Catarina a respeito de suas percepções sobre questões de gênero, violência e políticas públicas.

PALAVRAS-CHAVE: Políticas Públicas; Violência de Gênero; Mulheres.

ABSTRACT: This article contextualizes the advances of the Maria da Penha Law in relation to public policies of gender and combating violence against women during the eleven years since this law was implementation. The research is the result of a dissertation entitled “The attributions of women's police stations in Santa Catarina in the context of gender relations and the national policy to combat violence against women", which analyzed the regulatory powers of the Santa Catarina Women's Police Stations, the regulations that exist in the scope of the Santa Catarina Civil Police, and the new activities required by the Police, as provided for in the Maria da Penha Law. For this article, we analyze the interviews conducted in the qualitative research model with the delegates who work in the Santa Catarina Women's Delegacies, regarding their perceptions on issues of gender, violence and public policies.

KEYWORDS: Public Policies; Gender Violence; Women. 
UNIVALI

UNIVERSIDADE DO VALE DO ITAJAÍ

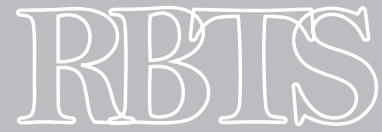

Revista Brasileira de Tecnologias Sociais 


\section{INTRODUÇÃO}

Há 11 anos a Lei Maria da Penha foi criada com o objetivo de coibir a violência doméstica e familiar contra a mulher por meio de uma composição institucional de medidas de integração entre os Poderes e os Entes da Federação para assistir às mulheres, além de endurecer as respostas àquelas agressões contra a mulher cometidas no âmbito privado. $\mathrm{O}$ âmbito doméstico e familiar ainda é um dos ambientes em que a violência de gênero contra a mulher mais se revela de modo estrutural. Em recente pesquisa do Instituto de Pesquisa Econômica Aplicada ${ }^{1}$ (IPEA) foi demonstrado, infelizmente, uma considerável tolerância às formas de violências praticadas no interior do lar justamente pelo fato de não serem reconhecidas, pelos entrevistados, como violências, apenas como problemas domésticos.

Um dos objetivos era entender a percepção acerca das violências contra as mulheres respondidas por homens e mulheres de distintos perfis sociais. Foi possível observar a premente necessidade de inserir o tema da violência doméstica e familiar contra as mulheres na agenda pública estatal, a fim de superar o entendimento social da violência apenas como uma questão privada e de foro íntimo. Conforme aponta o documento, 78,7\% dos entrevistados concordaram com a frase "o que acontece com o casal em casa não interessa aos outros", $82 \%$ acreditam que "em briga de marido e mulher, não se mete a colher" e $89 \%$ que "roupa suja se lava em casa”. Inacreditavelmente, permanece este imaginário social que tolera práticas de violências a despeito de todas as campanhas e políticas públicas de gênero consolidadas no Brasil desde a década de 1970, quando estas frases povoavam o senso comum e a consciência coletiva de uma grande parcela da sociedade brasileira. Por outro lado, há uma contraposição a estas ideias quando o tema se refere à violência física, que demonstrou um alto grau de concordância (91\%) com a frase "homem que bate na esposa tem que ir para a cadeia". Ou seja, as demais formas de violência ocorridas no interior do lar, desde que não sejam de caráter físico, são amplamente toleradas. Outro exemplo é a concordância com a frase "a questão da violência contra as mulheres recebe mais importância do que merece”, o que sinaliza uma resistência ao debate. Ora, a agenda feminista e as pautas dos movimentos de mulheres nos últimos 40 anos têm enfatizado justamente a superação destas práticas e representações com vistas à elaboração de uma agenda feminista estatal e de uma rede de articulação social e política que priorize a emancipação da mulher contra qualquer forma de violência.

Diante destes dados e da persistência de práticas e representações estruturais das violências de gênero contra as mulheres, este artigo contextualiza os avanços da Lei Maria da Penha em relação às políticas públicas de gênero e de enfrentamento à violência contra as mulheres no marco dos 11 anos da implementação desta lei. A partir de uma dissertação realizada no âmbito do Mestrado em Gestão de Políticas Públicas da UNIVALI, foram analisadas as entrevistas realizadas com os/as Delegados/as que atuam nas Delegacias da Mulher de Santa Catarina a respeito de suas percepções sobre questões de gênero, violência e políticas públicas.

\section{AS POLÍTICAS PÚBLICAS DE GÊNERO, DE ENFRENTAMENTO À VIO- LÊNCIA CONTRA AS MULHERES E A LEI MARIA DA PENHA}

O processo legislativo que culminou, em 07 de agosto de 2006, com a publicação da Lei 11.340, possibilitou a criação de diversos mecanismos para coibir e prevenir a violência doméstica

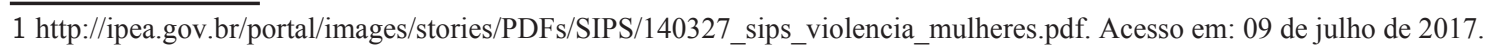


e familiar contra a mulher, além de dispor sobre a criação dos Juizados de violência doméstica e familiar, e estabelecer medidas de assistência e proteção às mulheres. É importante lembrar, entretanto, que a criação da Lei Maria da Penha foi resultado de uma condenação do Brasil, na Comissão Interamericana de Direitos Humanos da Organização dos Estados Americanos (OEA), movida por denúncia de organismos de defesa dos direitos humanos. A referida Comissão entendeu que o Estado brasileiro se omitiu no caso das duas tentativas de homicídio sofridas pela Maria da Penha Fernandes, perpetrados por seu marido, restando impune o autor dos crimes. Assim, como condenação, o Brasil precisou realizar o julgamento do agressor e também elaborar uma lei específica para os casos de violência doméstica, o que desencadeou o processo legislativo que deu origem à publicação da Lei Maria da Penha. Diversos foram os movimentos de mulheres que tiveram ações significativas para a efetivação de políticas de direitos, grande parte oriunda da classe média e alta, e também de grupos religiosos de mulheres, como o Marianismo, reformulado com a Teologia da Libertação, dos quais originaram grupos comunitários como as Comunidades Eclesiásticas de Base que se dedicavam às ações sociais e políticas em prol dos trabalhadores e das classes mais pobres, e estes grupos frequentemente eram liderados por mulheres (apesar de a Igreja olhar para as mulheres apenas como um grupo social oprimido). Como resultado destas mobilizações e como forma de cobrar do Estado respostas mais contundentes e eficazes contra as violências sofridas pelas mulheres, organizou-se a Política Nacional de Enfrentamento à Violência contra as Mulheres com uma definição mais ampla sobre violência, fundamentada na Convenção de Belém do Pará (1994), segundo a qual a violência contra a mulher constitui "qualquer ação ou conduta, baseada no gênero, que cause morte, dano ou sofrimento físico, sexual ou psicológico à mulher, tanto no âmbito público como no privado”, compreendendo:

1) A violência doméstica ou em qualquer outra relação interpessoal, em que o agressor conviva ou haja convivido no mesmo domicílio que a mulher e que compreende, entre outras, as violências física, psicológica, sexual, moral e patrimonial (Lei 11.340/2006); 2) A violência ocorrida na comunidade e seja perpetrada por qualquer pessoa e que compreende, entre outros, violação, abuso sexual, tortura, tráfico de mulheres, prostituição forçada, seqüestro e assédio sexual no lugar de trabalho, bem como em instituições educacionais, estabelecimentos de saúde ou qualquer outro lugar; 3) A violência perpetrada ou tolerada pelo Estado ou seus agentes, onde quer que ocorra (violência institucional). (BRASIL, 2011 b, p. 19)

Esta nova compreensão de violência de gênero foi fortalecida a partir da IV Conferência Mundial sobre as Mulheres em Beijin (1995), quando então se delineou uma estratégia de abordagem reconhecida como "transversalidade de gênero", tema emergente da agenda de gênero que significa garantir a incorporação de melhorias para as mulheres em todas as dimensões: econômica, política, cultural e social, em aspectos como remuneração, segurança social, educação, partilha nas responsabilidades profissionais e familiares, além de paridade nos processos de decisão. Para Lourdes Bandeira (2005, p.5), a transversalidade de gênero representa uma "matriz que permite orientar uma nova visão de competências e responsabilização dos agentes públicos em relação à superação das assimetrias de gênero, nas e entre as distintas esferas do governo."

Esta nova agenda de gênero para o séc. XXI, de acordo com Farah (2004, p.58), pautavase pela plataforma de ação da IV Conferência Mundial sobre as Mulheres, dada a necessidade de sua efetiva implementação, composta pelas seguintes diretrizes: 1) Violência, 2) Saúde, 3) Meninas 
e adolescentes, 4) Geração de emprego e renda, 5) Educação, 6) Trabalho, 7) Infraestrutura urbana e habitação; 8) Questão agrária; 9) Incorporação da perspectiva de gênero por toda política pública (transversalidade); 10) Acesso ao poder político e empowerment:

Criação de programas que atendam mulheres vítimas de violência doméstica e sexual, incluindo atenção integral (jurídica, psicológica e médica) e criação de abrigos. Formulação de políticas que articulem medidas na área da assistência e da segurança pública, incluindo a aplicação de medidas repressivas e preventivas mais efetivas.

É com base na plataforma de ação elaborada na Conferência que os países participantes, entre eles o Brasil, passaram a estruturar a agenda pública nos anos subsequentes, pensando a questão de gênero nas políticas públicas. No Brasil, em 2003, foi criada a Secretaria de Políticas para Mulheres, ligada à Presidência da República. Posteriormente, com a participação de setores da sociedade civil, com base na I Conferência Nacional para Mulheres, realizada em 2004, foi criado o Plano Nacional de Políticas para Mulheres. Em 2007, foi realizada a II Conferência, lançando-se, no ano seguinte, o II Plano Nacional de Políticas para Mulheres, cuja vigência foi até 2015.

É neste contexto de amplo exercício de uma cidadania de gênero e de um esforço coletivo de organização de políticas de gênero que se dá a promulgação da Lei Maria da Penha, cujo maior mérito foi conceituar violência doméstica e familiar como uma relação com ação ou omissão baseada no gênero:

Art. $5^{\circ}$ Para os efeitos desta Lei, configura violência doméstica e familiar contra a mulher qualquer ação ou omissão baseada no gênero que lhe cause morte, lesão, sofrimento físico, sexual ou psicológico e dano moral ou patrimonial: I - no âmbito da unidade doméstica, compreendida como o espaço de convívio permanente de pessoas, com ou sem vínculo familiar, inclusive as esporadicamente agregadas; II - no âmbito da família, compreendida como a comunidade formada por indivíduos que são ou se consideram aparentados, unidos por laços naturais, por afinidade ou por vontade expressa; III - em qualquer relação íntima de afeto, na qual o agressor conviva ou tenha convivido com a ofendida, independentemente de coabitação. Parágrafo único. As relações pessoais enunciadas neste artigo independem de orientação sexual.

A introdução do dispositivo "gênero" foi um divisor de águas na classificação da violência, nas palavras de Machado (2016, p.12):

O dispositivo destituiu os discursos sobre as violências de uma perspectiva simplificadora. Impediu as pessoas de dizer que a questão era exclusivamente jurídica, exclusivamente afeita à conjugalidade, exclusivamente praticada por homens (embora saibamos, obviamente, que em boa parte o é e assim reforçam as últimas estatísticas do mapa de morte de mulheres, confirmando que mais de $40 \%$ dos feminicídios registrados na última década, no Brasil, foram perpetrados por companheiros, maridos ou ex-companheiros, Waiselfisz, 2012). A categoria gênero conferiu a complexidade necessária para a prática das violências contra mulheres, ressaltando seu caráter estrutural implicado em redes de poder, e vivenciadas em diversos contextos.

Sobre este aspecto, é importante ressaltar que, teoricamente, as violências doméstica e familiar são categorias distintas, e que merecem ser especificadas, pois também diferem da violência de gênero, conforme já enunciado por Saffioti (1999, p. 82-83): 
A expressão violência doméstica costuma ser empregada como sinônimo de violência familiar e, não raramente, de violência de gênero. [ …] Não há maiores dificuldades em se comprometer a violência familiar, ou seja, aquela que envolve membros de uma mesma família extensa ou nuclear, levando-se em conta a consanguinidade e a afinidade. Compreendida na violência de gênero, a violência familiar pode ocorrer no interior do domicílio ou fora dele, embora seja mais frequente no primeiro caso. A violência intrafamiliar extrapola os limites do domicílio. [...] A violência doméstica apresenta pontos de sobreposição com a familiar, podendo também atingir pessoas que, não pertencendo à família, vivem, parcial ou integralmente, no domicílio do agressor, como é o caso de agregados e empregadas (os) domésticas (os). Estabelecido o domínio de um território, o chefe, via de regra um homem, passa a reinar quase incondicionalmente sobre seus demais ocupantes. O processo de territorialização do domínio não é puramente geográfico, mas também simbólico.

Quanto à violência de gênero, a autora ressalta que concerne preferencialmente às relações homem-mulher, o que não significa que uma relação entre duas mulheres ou dois homens não possa se enquadrar nesta categoria. Saffioti (2001, p. 115) ressalta que a violência de gênero possui conceito amplo, abrangendo vítimas mulheres, crianças e adolescentes de ambos os sexos:

No exercício da função patriarcal, os homens detêm o poder de determinar a conduta das categorias sociais nomeadas, recebendo autorização ou, pelo menos, tolerância da sociedade para punir o que se lhes apresenta como desvio. Ainda que não haja nenhuma tentativa, por parte das vítimas potenciais, de trilhar caminhos diversos do prescrito pelas normas sociais, a execução do projeto de dominação-exploração da categoria social homens exige que sua capacidade de mando seja auxiliada pela violência. Com efeito, a ideologia de gênero é insuficiente para garantir a obediência das vítimas potenciais aos ditames do patriarca, tendo esta necessidade de fazer uso da violência. Nada impede, embora seja inusitado, que uma mulher pratique violência física contra seu marido/ companheiro/namorado. As mulheres como categoria social não têm, contudo, um projeto de dominação-exploração dos homens.

Entre outras inovações ao tema do enfrentamento à violência doméstica e familiar, a referida lei definiu o que é violência doméstica e familiar como toda aquela baseada nas relações de gênero e praticada no âmbito da unidade doméstica, familiar ou em qualquer relação íntima de afeto e impôs a vedação de aplicação de cestas básicas, prestações pecuniárias ou penas isoladas de multa aos casos de violência. ${ }^{2} \mathrm{O}$ artigo 12 da Lei descreve procedimentos a serem adotados com relação ao registro de ocorrência de violência doméstica, como a obrigação da autoridade policial ouvir a ofendida, lavrar o boletim de ocorrência, tomar a representação a termo, colher as provas do crime, determinar que se proceda ao exame de corpo de delito e outras perícias, ouvir o agressor e as testemunhas, juntar os antecedentes criminais do agressor e remeter o inquérito policial ao

2 A Lei Maria da Penha também vedou a aplicação dos artigos da lei dos juizados especiais criminais, a Lei 9.099/95. Desta forma, os crimes de violência doméstica ou familiar cometidas contra mulheres, independentemente da quantidade de pena, somente serão processados mediante inquérito policial. No caso de prisão em flagrante, não há possibilidade de confeccionar Termo Circunstanciado e liberar o agressor: será lavrado Auto de Prisão em Flagrante. Também em decorrência da inaplicabilidade da lei 9.099/95, o crime de lesão corporal leve é considerado de ação pública incondicionada, ou seja, o processo ocorre independente de manifestação de vontade da vítima. O contrário também é válido: mesmo que a vítima não deseje processar o autor, a Autoridade Policial é obrigada a instaurar o inquérito, produzir as provas e remeter o resultado da investigação ao Juizado de Violência Doméstica. Essa situação é particularmente importante no momento da prisão em flagrante, a qual deverá ser executada independentemente da vontade da vítima - não há possibilidade de desistir na delegacia, ou de fazer o boletim apenas para dar "um susto" no agressor. 
juiz no prazo legal. Além disso, o referido artigo impõe prazo para que a autoridade policial remeta o pedido da ofendida para concessão de medidas protetivas de urgência ${ }^{3}$. A Lei previu, ainda, a criação de Juizados de Violência Doméstica e Familiar contra a Mulher, com competência cível e criminal para processo e julgamento das demandas relacionadas à violência doméstica e familiar, também procurou vedar a entrega, pela mulher em situação de violência, de intimação da Delegacia ao agressor, conforme preconiza o art. 21, em seu parágrafo único, a utilização de policiais e oficiais de justiça para efetuar a notificação ao agressor. A Lei também forneceu instrumentos às mulheres relativos à ordem familiar como a guarda e a educação de filhos, a pensão alimentícia, a moradia provisória durante o processo. Além disso, a Lei prevê diversas medidas integradas de assistência à mulher em situação de violência, demandando a organização de diversos serviços em rede: Poder Judiciário, Ministério Público, Defensoria Pública, segurança pública, assistência social, saúde, educação, trabalho e habitação.

As ações de enfrentamento à violência contra mulheres não se restringem às ações de segurança e assistência, mas objetivam a criação de diversos serviços, como centros de referência, defensorias públicas, serviços de responsabilização e educação do agressor, promotorias e varas especializadas, dentre outros. Em consonância com a construção dos Planos Nacionais de Políticas para Mulheres, o art. $8^{\circ}$ da Lei assegura que as políticas públicas devem promover valores ligados à equidade de gênero e uma educação escolar baseada na igualdade e nos direitos humanos, a fim de se estabelecer um novo paradigma de socialização que não reproduza preconceitos e formas reiteradas de violências de gênero. Neste sentido, a Política Nacional de Enfrentamento à Violência contra Mulheres considera o enfoque de gênero fundamental para compreender estes tipos de violência:

A violência contra as mulheres só pode ser entendida no contexto das relações desiguais de gênero, como forma de reprodução do controle do corpo feminino e das mulheres numa sociedade sexista e patriarcal. As desigualdades de gênero têm, assim, na violência contra as mulheres, sua expressão máxima que, por sua vez, deve ser compreendida como uma violação dos direitos humanos das mulheres. (BRASIL, 2011 b, p. 21).

O texto reconhece, ainda, que a violência de gênero contra as mulheres remete "a um fenômeno multifacetado, com raízes histórico-culturais, é permeado por questões étnico-raciais, de classe e de geração" (BRASIL, 2011 b, p. 21), requerendo do Estado e dos demais agentes uma abordagem intersetorial e multidimensional, que envolva diversos setores, como saúde, educação, assistência social, segurança pública, cultura, justiça e outros. Por isso, a política não se denomina combate à violência, e sim enfrentamento, pois "a noção de enfrentamento não se restringe à questão do combate, mas compreende também as dimensões da prevenção, da assistência e da garantia de direitos das mulheres" (BRASIL, 201 b, p. 25). A Política Nacional de Enfrentamento à Violência contra as Mulheres é composta de 06 diretrizes que devem ser implementadas em consonância ao Pacto Nacional de Enfrentamento à Violência Contra a Mulher, como parte de sua agenda social, lançado em 2007 pelo Governo Federal, conforme a Secretaria de Políticas para Mulheres (BRASIL, 2011a, p.11). A proposta inicial do Pacto era estruturar as ações em torno de quatro áreas, os quais foram ampliados, no ano de 2011, para cinco eixos: 1) Garantia da aplicabilidade

3 Tramita no Congresso Nacional o Projeto de Lei nº 6433/2013 que altera e acrescenta dispositivos à Lei Maria da Penha. Entre as principais mudanças, o projeto prevê que o delegado de polícia poderá aplicar de imediato, em ato fundamentado, isolada ou cumulativamente, as medidas protetivas de urgência previstas nos incisos I a IV do art. 22, no inciso I do art. 23 e no inciso I do art. 24, comunicando em seguida ao juiz competente, ao Ministério Público, à vítima e, se possível, ao agressor, que será cientificado das medidas aplicadas e das penalidades em caso de desobediência. (GHISI et al.,2016) 
da Lei Maria da Penha; 2) Ampliação e fortalecimento da rede de serviços para mulheres em situação de violência; 3) Garantia da segurança cidadã e acesso à Justiça; 4) Garantia dos direitos sexuais e reprodutivos, enfrentamento à exploração sexual e ao tráfico de mulheres; 5) Garantia da autonomia das mulheres em situação de violência e ampliação de seus direitos (BRASIL, 2011a, p.12). O Pacto e as ações nele propostas se baseiam em três premissas: a transversalidade de gênero, a intersetorialidade e a capilaridade:

A transversalidade de gênero visa garantir que a questão de violência contra a mulher e de gênero perpasse as mais diversas políticas públicas setoriais. A intersetorialidade, por sua vez, compreende ações em duas dimensões: uma envolvendo parcerias entre organismos setoriais e atores em cada esfera de governo (ministérios, secretarias, coordenadorias, etc.); e outra, implica uma maior articulação entre políticas nacionais e locais em diferentes áreas (saúde, justiça, educação, trabalho, segurança pública, etc.). Dessa articulação decorre a terceira premissa que diz respeito à capilaridade destas ações, programas e políticas; levando a proposta de execução de uma política nacional de enfrentamento à violência contra as mulheres até os níveis locais de governo. (BRASIL, $2011 \mathrm{a}, \mathrm{p} .24)$.

Como resultantes deste Pacto, no âmbito do Governo federal brasileiro, foram estabelecidas diferentes experiências na gestão de políticas transversais desde o ano de 2003, com a formulação do Plano Plurianual e com a criação das Secretarias de Política para as Mulheres (SPM) e de Igualdade Racial (SEPPIR).

Os avanços legais trazidos com a Lei Maria da Penha e as políticas públicas setoriais implementadas nos últimos anos traduzem as mais recentes discussões sobre as relações de gênero no campo das políticas públicas e da violência estrutural da sociedade brasileira a partir dos enfoques de gênero, como discute Barsted (2011, p.15):

Esse processo de luta por direitos, voltado para a eliminação de todas as formas de discriminação, incluindo a dominação masculina, apresenta, ao longo da Lei Maria da Penha, uma experiência bem sucedida de advocacy feminista das últimas três décadas, um conjunto de importantes avanços legislativos e de políticas públicas que não pode ser subestimado. A luta pelo direito a uma vida sem violência, que possibilitou a aprovação da Lei Maria da Penha, em 2006, é um caso exemplar de exercício de uma cidadania ativa expressa no discurso e na atuação das feministas no espaço público. Sintetiza, também, a longa interlocução das feministas com os poderes legislativo e executivo e aponta para a necessidade de investimentos contínuos no diálogo com o poder judiciário e as demais instituições da justiça.

Se os desafios para manter os direitos conquistados dentro de uma agenda política de gênero são enormes, não menos desafiador se apresenta a questão da eficácia social e jurídica da Lei Maria da Penha e das políticas públicas de enfrentamento às violências, afinal, não basta considerar o número de leis promulgadas ou o forte apelo social a uma conjuntura de demandas por direitos, ainda mais em um contexto tão delicado como o das violências de gênero. Cabe, aqui, destacar algumas críticas de estudiosas da Criminologia Feminista que apontam para a necessidade de superação daquilo que Vera Regina P. de Andrade (2016, p.105) chama de "demanda neocriminalizadora” que acabou por "eleger o controle penal como o mecanismo prioritário” para resolver o problema da violência de gênero. Andrade tece críticas aos movimentos feministas ao 
reconhecer neles alguns paradoxos desta demanda neocriminalizadora que oscilava entre a postura descriminalizadora/despenalizadora de condutas tipificadas como crimes sexuais (adultério, aborto, casas de prostituição, etc.) e a postura que exigia por parte do Estado uma maior criminalização de condutas como a violência doméstica e familiar contra a mulher, assédio sexual, estupro e o agravamento de penas para os casos de assassinatos de mulheres. É o que diz também Karam ao ressaltar "os paradoxais desejos punitivistas dos movimentos feministas", cujo efeito é "meramente simbólico e vazio de significado, porque reprodutoras da dor e do sofrimento associados ao Sistema Punitivo de um modo geral.” (KARAM apud MACHADO, 2016, p. 14). De fato, o Estado parece ter "cumprido a sua parte" com a promulgação da Lei Maria da Penha e mais recentemente a Lei do Feminicídio, o que apenas reforça a eficácia desta demanda neocriminalizadora muitas vezes consentida e amparada pelas feministas que defendem o feminismo institucional. Em contrapartida, outros segmentos feministas têm observado a "necessidade de questionar o recurso ao sistema penal assim como a importância de buscar meios alternativos mais sintonizados com os objetivos feministas" (ANDRADE, 2016, p. 82).

Dentre estes objetivos, a autora sugere tanto a superação das lógicas de seletividade e honestidade presentes no sistema penal quanto a superação do sexismo patriarcalista, que corrobora a cultura da judicialização e da criminalização, além de ilusoriamente oferecer proteção real para as mulheres, como comprovam diversas pesquisas sobre a "eficácia invertida" da Lei Maria da Penha que resulta quase sempre na (re)vitimização da mulher e na perpetuação dos ciclos de violência. Em oposição ao que assevera Andrade, Machado entende que as estratégias criminalizadoras adotadas pelos movimentos feministas não devem ser interpretadas unicamente, ou de uma maneira simplista, como meras tentativas de solução à violência contra a mulher, mas devem ser compreendidas como canais de enfrentamento contínuo do problema os quais permitem não apenas uma alteração nominativa, mas trazem resultados concretos na superação de um problema anteriormente entendido como pessoal e, depois da lei, passou a ser de ordem pública. Em suas palavras, estas estratégias são canais que viabilizam "a produção de estatísticas, a criação de novos serviços de atendimentos, de novas estruturas de políticas públicas, enfim, a ampliação do espectro de cidadania das mulheres", além de dar "uma valorização incontornável de intervenções psicossociais e a um conjunto de mecanismos protetivos, formativos e educativos que visam prevenir tais violências, compondo sua dimensão protetiva” (MACHADO, 2016, p. 16).

\section{Delegacias da Mulher de Santa Catarina: percepÇões Sobre GÊNERo,} VIOLÊNCIA E POLÍTICAS PÚBLICAS

A fim de observar uma parte destas estratégias, foram entrevistados 28 Delegados/ Delegadas de Polícia Civil do Estado de Santa Catarina titulares das especializadas em funcionamento. Destes, 19 responderam à pesquisa com questões abertas sobre suas percepções de gênero, violência e políticas públicas. Na primeira pergunta: “O que você entende por gênero?”, o6 respostas continham a palavra "sociedade" ou "relações sociais", ou seja, para esses delegados, gênero se relaciona com "papéis atribuídos pela sociedade”, ou "construção social” sobre os sexos:

Entendo que gênero é um termo utilizado no intuito de superar os determinismos biológicos que diferem os sexos feminino e masculino, no intuito de redefinir as relações entre homens e mulheres e questionar o lugar e os papéis que eles ocupam na sociedade e as relações de poder que se estabelecem. (....) Trata-se não só da distinção entre homens e mulheres, mas nas relações sociais entre eles 
estabelecidas e também nos diferentes papeis por eles ocupados na sociedade. (...) Gênero são as atribuições/estereótipos que determinada sociedade atribui as pessoas, as classificando em homens ou mulheres. (...) A palavra gênero tem alguns significados. Contudo, relacionado ao tema proposto (Delegacias Especializadas), gênero é a diferença existente entre o "mundo" masculino e o feminino; são as características atribuídas a cada sexo pela sociedade. (...) Tratase de uma construção social que define o que seja ser homem ou ser mulher. (...) Refere-se à identidade adotada ou atribuída a uma pessoa de acordo com seus genitais, psicologia ou seu papel na sociedade.

As principais categorias mobilizadas pelos/as Delegados/as em suas definições de gênero podem ser agrupadas em 02 grandes grupos, que serão chamadas de: 1) Sistema sexogênero, referente à crítica aos determinismos biológicos, características sexuais de acordo com seus genitais; 2) Sistema sociedade-gênero, referente ao entendimento do gênero como construção social da diferença sexual que busca questionar lugares, papéis/atribuições/estereótipos, relações sociais, identidade e relações de poder entre homens e mulheres. Tais respostas mostram o resultado do aprimoramento destes profissionais nos cursos de complementação, qualificação e formação em gênero a partir da noção de diferença sexual concebida em termos de dominação e controle de mulheres a partir dos lugares e papéis que elas ocupam na sociedade. Também foi possível observar 03 respostas que identificaram as relações de gênero às formas múltiplas de violência, mas preferiram usar o termo "violência contra a mulher" e não "violência de gênero" ao relatar crimes específicos contra determinados grupos vulneráveis de mulheres, meninas, adolescentes e idosas. Pode-se dizer que existe, por parte desses profissionais, a compreensão do gênero como uma relação de hipossuficiência, de desigualdade, cuja compreensão de violência é atravessada pelas formas de poder exercidas sobre tais grupos em situação de vulnerabilidade. Esta compreensão é problemática à medida em que associa a violência contra as mulheres apenas para os grupos de mulheres em situação de vulnerabilidade econômica. Ao mesmo tempo em que algumas pesquisas demonstram que as mulheres vítimas de violência doméstica são submissas, economicamente dependentes e com baixo poder de decisão sobre os atos da própria vida, esse nem sempre é o perfil, pois conforme observa Nizer (2010, p. 150), grande parte das mulheres que procuraram a Delegacia da Mulher de Florianópolis trabalha e tem condições de sustentar a si e aos filhos.

Quando questionados se consideram que a Delegacia atende às demandas relacionadas à violência de gênero, 18 responderam positivamente, sendo que apenas uma resposta foi negativa:

De forma alguma. As Delegacias da Mulher têm sido utilizadas pela população como o único espaço público de reclamação de suas questões pessoais. As mulheres que procuram a Delegacia buscam por soluções que só um atendimento psicossocial e jurídico poderia resolver. Pela ausência desse serviço, a mulher se frustra e o trágico resultado é a criminalização das questões familiares de pessoas menos esclarecidas e, geralmente, de baixa renda. Cabe esclarecer que as pessoas que verdadeiramente sofrem violência de gênero não procuram as Delegacias de Polícia, por medo, por desconhecimento de seus direitos e por serem resilientes às violências sofridas.

$\mathrm{O}(\mathrm{a})$ Delegado(a) acredita que as pessoas que realmente sofrem violência de gênero não têm procurado a delegacia - essa percepção provavelmente ocorre diante do perfil diversificado de 
mulheres que procuram os serviços policiais. Aqueles que consideram que a Delegacia atende às demandas de gênero justificaram sua posição afirmando cumprimento às demandas da Lei Maria da Penha, que exige a ocorrência de violência baseada no gênero, além da previsão de atendimento a todos os crimes em que as vítimas sejam mulheres. Também foi questionado se eles/elas consideram que a Delegacia tem implantado Políticas Públicas de Gênero ou Políticas Públicas para Mulheres, e se eles entendem haver diferença entre tais políticas, 06 Delegados entenderam que a Delegacia não tem implantado políticas públicas de gênero e/ou políticas para as mulheres, em consonância com a resposta anteriormente discutida, mas em flagrante contradição com as respostas positivas dadas em relação ao cumprimento, por parte das Delegacias, às demandas relacionadas à violência de gênero. Ora, se as Delegacias atendem a estas demandas, então como dizer que as Delegacias não têm implantado políticas públicas de gênero e/ou políticas para as mulheres? Nas respostas oferecidas, 04 responderam que as políticas públicas de gênero competem ao Poder Executivo Federal, Estadual e Municipal, sendo que à Delegacia cabe apenas orientar as usuárias sobre quais políticas estão disponíveis, de acordo com o perfil e as necessidades apresentadas pelas mulheres e o9 responderam que se limitam ao trabalho da Delegacia as demandas de procedimentos policiais a serem encaminhadas para o Poder Judiciário, não conseguindo participar de fóruns, cursos, debates. Estas falas são preocupantes, pois evidenciam certa frustração dos profissionais que esperavam participar mais ativamente da política de enfrentamento à violência contra as mulheres. Ao mesmo tempo, as afirmativas demonstram certo desconhecimento sobre tais políticas, que passam necessariamente pelo registro das ocorrências, da investigação dos crimes e da responsabilização do agressor, atividades que tornam visíveis as violências, produzem estatísticas, promovem o encorajamento e oportunizam o acolhimento das queixas e das denúncias, atividades imprescindíveis para a transformação deste cenário de não cidadania por parte daquelas que sofrem, diariamente, violências de todo o tipo. Quanto à diferença entre políticas de gênero e políticas para mulheres, apenas 01 Delegado/a ressaltou não haver distinção, enquanto apenas 04 Delegados/as responderam afirmativamente, os demais não responderam:

Há diferenças sim, a política pública de gênero tem uma abrangência muito maior do que a política pública para mulheres, abrangendo não só estas, mas também toda relação entre pessoas, seja do mesmo sexo ou não, em que exista vulnerabilidade e dependência de uma parte em relação a outra, com ressalvas para a discussão doutrinária acerca das relações homoafetivas masculinas, onde ainda há muita discussão e polêmica sobre o tema.(...) Sim, há diferença entre políticas públicas de Gênero e Políticas Públicas para Mulheres, pois as primeiras são voltadas a garantia da igualdade material entre homens e mulheres, enquanto as segundas visam apenas melhorar as condições das mulheres sem estarem baseadas nas preocupações atinentes as diferenças de gênero.(...)Entendo que há diferença entre política pública de gênero e política pública para mulheres, porque a primeira teria o intuito de chegar-se à equidade tão esperada.

Pode-se verificar que não há uma percepção da atividade policial especializada como parte da política pública de enfrentamento à violência de gênero, o que sinaliza a dificuldade, apontada por Marta Farah (2004), da incorporação da perspectiva de gênero pelas políticas públicas e seus atores/atrizes. Apesar da lei prever medidas integradas de assistência à mulher por parte da rede de atendimento (Poder Judiciário, Ministério Público, Defensoria Pública e órgãos ligados às políticas de segurança pública, assistência social, saúde, educação, trabalho e habitação), ainda há um longo caminho para que esta rede de serviços alcance efetividade. 


\section{CONSIDERAÇÕES FINAIS}

As políticas de enfrentamento à violência contra mulheres ainda se mostram bastante frágeis e com uma série de obstáculos que se interpõem na vivência de uma cidadania de gênero pelas mulheres. Cumpre lembrar que a superação do sexismo patriarcal vigente na cultura política brasileira anda de mãos dadas com o fortalecimento do viés feminista e de gênero para as políticas públicas, não se devendo perder de vista a longa trajetória das políticas públicas de gênero e das políticas de enfrentamento das violências, tampouco deixar de transversalizar estas mesmas políticas na gestão pública. Nesta pesquisa, a função da Delegacia de Polícia é essencial e a percepção acerca da importância da especializada está presente na fala dos Delegados/as que consideram a Delegacia como promotora de políticas públicas. Estes entendem que a própria implantação da Delegacia da Mulher já é uma política pública para mulheres e assim se consolida por possuir atendimento específico para o público feminino, quando fornece apoio psicossocial no local, encaminhamento a centros especializados em acolhimento social, encaminhamento de pedidos de medidas protetivas, encaminhamento à Casa Abrigo da Mulher, etc.

Algumas falas evidenciaram, também, um descontentamento com as políticas públicas de segurança, as quais privilegiam crimes de maior repercussão midiática, fazendo com que as delegacias sejam carentes em recursos, em efetivo qualificado e em equipamentos, apesar da grande demanda de trabalho. Além disso, alguns delegados mencionaram o fato de que a Delegacia atende diversos públicos além da violência contra a mulher, como o caso das crianças, adolescentes e idosos, o que aumenta o número de procedimentos policiais e faz com que, muitas vezes, as Delegacias cumpram os preceitos legais de forma mecânica e sem a devida sensibilidade e atenção que os casos merecem.

Diante desta reflexão, os avanços jurídicos e políticos aqui apresentados refletem apenas uma parte do caminho percorrido. A outra parte, como dizia Fernando Pessoa, se faz caminhando e é na superação dos obstáculos culturais e políticos que se erguem contra a cidadania de gênero e feminista que este caminho se faz.

\section{REFERÊNCIAS}

ANDRADE, V. R. P. de. Sistema penal máximo x Cidadania mínima. Porto Alegre: Livraria do Advogado, 2016.

BANDEIRA, L. Fortalecimento da Secretaria Especial de Políticas para as mulheres: avançar na transversalidade da perspectiva de gênero nas políticas públicas. Brasília: CEPAL/SPM, 2005.

BARSTED, L. L. Lei Maria da Penha: uma experiência bem-sucedida de advocacy feminista. In: CAMPOS, C. H. (Org.). Lei Maria da Penha, comentada em uma perspectiva jurídico-feminista. Rio de Janeiro: Lumen Juris, 2011, p.14-15.

BRASIL. Secretaria de Políticas para as mulheres. Pacto Nacional pelo Enfrentamento à Violência contra as Mulheres. Brasília, 2011a.

BRASIL. Secretaria de Políticas para as Mulheres. Política Nacional de Enfrentamento à Violência contra as Mulheres. Brasília, $2011 \mathrm{~b}$.

COSTA, A. A. A. O Movimento Feminista no Brasil: dinâmica de uma intervenção política. In: PISCITELLI, 
A. et al. (Org.). Olhares Feministas. 1.ed. Brasília: UNESCO, 2009.

FARAH, M. F. S. Gênero e políticas públicas. Revista Estudos Feministas. [on-line]. v.12. n.1. Florianópolis, 2004. Disponível em: < http://www.scielo.br/pdf/ref/v12n1/21692.pdf>. Acesso em: 12 set 2012.

GHISI, A. S. S.; D’AVILA, P. M. Z.; PAIXÃO, G. de J. da. Enfrentamento à violência contra as mulheres: as atribuições das delegacias da mulher em Santa Catarina. In: VEIGA, A. M.; LISBOA, T. K.; WOLF, C. S. Gênero e Violências: Diálogos Interdisciplinares. Florianópolis: Ed. do Bosque/CFH/UFSC, 2016, p. 202-237.

IPEA, Tolerância social à violência contra as mulheres. Disponível em: http://ipea.gov.br/portal/images/ stories/PDFs/SIPS/140327_sips_violencia_mulheres.pdf. Acesso em: 09 jul. 2017.

KARAM, M. L. Os paradoxais desejos punitivos de ativistas e movimentos feministas. In: MACHADO, I. Lei Maria da Penha: conquistas e desafios. In: VEIGA, A. M.; LISBOA, T. K.; WOLF, C. S. Gênero e Violências: Diálogos Interdisciplinares. Florianópolis: Ed. do Bosque/CFH/UFSC, 2016, p. 08-26.

NIZER, J. de P. Agressões contra mulheres em Florianópolis segundo os boletins de ocorrência registrados nas Delegacias da Capital em 2006. In: CÓRDOVA, L. F. N. et al. (Org.). Os 25 anos da "Delegacia da Mulher” de Florianópolis: impasses e perspectivas para a 'base de pantera'. Florianópolis: UFSC/CFH/ NUPPE, 2010.

SAFFiOTI, H. I. B. Já se mete a colher em briga de marido e mulher. São Paulo Perspectiva, v.13, n.4, dez 1999. p.82-91.

SAFFIOTI, H. I. B Contribuições feministas para o estudo da violência de gênero. Cadernos Pagu, n.16, 2001. p.115-136. 